\title{
Seroprevalence of anti-SARS-CoV-2 total antibody is higher in younger Austrian blood donors
}

\author{
Lisa Weidner ${ }^{1} \cdot$ Verena Nunhofer $^{2} \cdot$ Christof Jungbauer $^{1} \cdot$ Alexandra Domnica Hoeggerl $^{2} \cdot$ Lydia Grüner $^{2}$. \\ Christoph Grabmer ${ }^{2} \cdot$ Georg Zimmermann ${ }^{3,4} \cdot$ Eva Rohde $^{2,5} \cdot$ Sandra Laner-Plamberger ${ }^{2,5}$ (1)
}

Received: 26 March 2021 / Accepted: 7 June 2021 / Published online: 16 June 2021

(c) The Author(s) 2021

\begin{abstract}
Purpose Frequently the infection with coronavirus 2 (SARS-CoV-2) can be asymptomatic or provoke only mild symptoms. These cases often remain unnoticed, so it is difficult to estimate the actual numbers of infections. Aim of this study was to determine the seroprevalence of anti-SARS-CoV-2 total antibody in Austrian blood donors.

Methods 20,228 blood donors aged between 18 and 72 years resident in four Austrian federal states were screened for antiSARS-CoV-2 total antibody between 5th of June and 4th of December 2020. To evaluate the impact of sex, age, AB0-blood group and donation period on the anti-SARS-CoV-2 seroprevalence, multiple logistic regression was done.

Results Our data reveal an anti-SARS-CoV-2 seroprevalence of $2.5 \%$ overall, significantly depending on the time point of blood donation: after the first Austrian lockdown the seroprevalence was lower compared to the following months, when the rate was constantly rising. While younger blood donors showed significantly higher seroprevalence, no differences were found concerning sex or AB0 blood group.

Conclusion Broad testing strategies are required to better determine the number of SARS-CoV-2 infections. Screening blood donors as a representative group for the adult population could be a valid tool to determine the number of recorded and unrecorded cases of SARS-CoV-2 infection.
\end{abstract}

Keywords Seroprevalence $\cdot$ COVID-19 $\cdot$ SARS-CoV-2 $\cdot$ Blood donation

\section{Introduction}

In December 2019, clusters of patients suffering from pneumonia were reported in China, caused by a novel coronavirus [1]. This enveloped RNA-virus belongs to the family

Sandra Laner-Plamberger

s.laner-plamberger@salk.at

1 Austrian Red Cross, Blood Service for Vienna, Lower Austria and Burgenland, Wiedner Hauptstraße 32, 1040 Vienna, Austria

2 Department for Transfusion Medicine, University Hospital of Salzburg (SALK), Paracelsus Medical University (PMU) Salzburg, Müllner-Hauptstraße 48, 5020 Salzburg, Austria

3 Team Biostatistics and Big Medical Data, IDA Lab Salzburg, PMU Salzburg, Strubergasse 16, 5020 Salzburg, Austria

4 Department of Research and Innovation, PMU Salzburg, Strubergasse 16, 5020 Salzburg, Austria

5 Spinal Cord Injury and Tissue Regeneration Centre Salzburg, PMU Salzburg, Strubergasse 21, 5020 Salzburg, Austria of beta-coronaviruses, causing coronavirus disease 2019 (COVID-19) [2]. This disease resembles severe acute respiratory syndrome (SARS) and Middle East respiratory syndrome (MERS), both caused by two other strains of coronaviruses $[3,4]$. Therefore, the World Health Organization (WHO) termed the novel virus "SARS-coronavirus-2 (SARS-CoV-2)" [https://www.who.int/emergencies/disea ses/novel-coronavirus-2019/technical-guidance/namingthe-coronavirus-disease-(covid-2019)-and-the-virus-thatcauses-it, accessed 03.05.2021]. The majority of SARSCoV-2 positively tested individuals are asymptomatic or develop mild, flu-like symptoms, such as cough, fever, headache and myalgia. While hyposmia and dysgeusia are described as common symptoms of this virus infection, occasionally dyspnoea, diarrhoea and nausea are reported as well [5]. However, more severe courses of COVID-19 feature acute respiratory distress syndrome (ARDS), sepsis, neurological complications and coagulation disorders among others. These severe courses are often associated with increased age or other comorbidities, such as respiratory 
diseases, diabetes, cardiovascular diseases or obesity [6]. Currently, the WHO assumes a mortality rate of 3-4\% [https://www.who.int/publications/i/item/WHO-2019-nCoVSci-Brief-Mortality-2020.1, accessed 03.05.2021].

By May 2021, over 150 million cases of SARS-CoV-2 infections were reported globally, with more than 3 million deaths (COVID-19 Map-Johns Hopkins Coronavirus Resource Center, jhu.edu, accessed 03.05.2021). However, the exact numbers of SARS-CoV-2 infections are difficult to determine. First, varying testing strategies of different countries lead to statistical variations. Second, countries with younger populations report less morbidity and mortality [7]. Furthermore, since the majority of infections cause mild to moderate symptoms or are even asymptomatic, these cases frequently remain unnoticed. Such cases are challenging the prevention of disease dissemination, since the infected individuals might further spread the virus without even noticing. To obtain accurate prevalence rates within the population, which could help governmental institutions and communities to make appropriate decisions to contain the virus dissemination, it might be helpful to determine the prevalence in a subgroup of the population. Blood donors represent a comparatively healthy subgroup of the adult population. The objective of this study was to determine the anti-SARS-CoV-2 total antibody seroprevalence among regular blood donors resident in four different federal states of Austria as a tool to monitor the epidemic within the Austrian population. In sum, 20,228 blood donors were screened between 5th of June and 4th of December 2020.

\section{Materials and methods}

\section{Sample collection}

We studied the serum samples of 20,228 donors, which were collected in the course of voluntary, non-remunerated whole blood donations in four federal states of Austria (Vienna, Lower Austria, Burgenland and Salzburg) from 5th June until 4th December 2020. In these four states live with 4.4 million people about $49.8 \%$ of the Austrian population (https://www.statistik.at/web_de/statistiken/menschen_und_ gesellschaft/bevoelkerung/index.html, accessed 18.03.2021).

Before donating blood, all donors had a brief health screening and had to complete a written questionnaire, including an informed consent on pathogen screening as a standard part of the blood donation process. Therefore, only individuals that appeared fit to donate at the time of the blood donation and had not reported symptoms of a common cold within the last two weeks or other health issues within a relevant time span before the donation were included. Samples of all blood donors admitted to regular blood donation with signed informed consent on pathogen screening and the use of rest material for research purposes were included. No further preselection (e.g. according to a putative previous SARS-CoV-2 infection) of sample material was done. Concerning demographics of donors, it is important to note that children ( $<18$ years) and individuals older than 72 years were not included in this study. Every sample represents an individual donor, in sum, 20,228 were included in this study.

\section{Serological testing}

Donor samples were screened for anti-SARS-CoV-2 total antibody (including IgM, IgG and IgA) using Elecsys AntiSARS-CoV-2 assay (ACOV2) total antibody electrochemiluminescence immunoassay (ECLIA, Roche Diagnostics, Basel Switzerland) using nucleocapsid (N) antigen as target on two independent cobas8000-e801 devices (Roche Diagnostics) according to manufacturer's instructions. The sensitivity and specificity given by the manufacturer is $100 \%$ ( $\geq 14$ days after SARS-CoV-2 NAT testing) and $99.81 \%$, respectively. The results of this semi-quantitative test are based on the sample signal to cut-off ratio, with values $<1.0$ corresponding to non-reactive (negative) results and values $\geq 1.0$ corresponding to reactive (positive) results. Reactive samples were subjected to a triple repeat measurement and considered positive for anti-SARS-CoV-2 if the repeated measurements were reactive as well. Less than $0.1 \%$ of reactive samples showed a non-reactive result in one out of three repeat measurements. To determine the specificity of the ACOV2 test, a subgroup of 82 reactive samples was also tested with Wantai SARS-CoV-2 Ab ELISA (Wantai Biological Pharmacy, Beijing, China) on BEP III analyser (Siemens Healthcare, Erlangen, Germany) according to manufacturer's instructions. As published earlier, the Wantai SARS-CoV-2 Ab ELISA showed a sensitivity of $98 \%$ and a good correlation with virus neutralisation test [8]. Therefore, it was considered as an acceptable confirmation test.

\section{Data collection and statistical analysis}

Data regarding age, sex and $\mathrm{AB} 0$-blood group of the donors included were retrieved from the blood bank information systems swisslab (Nexus-swisslab, Berlin, Germany; data from Salzburg) and Edgelab (Edge Laboratories, Lausanne, Switzerland; data from Vienna, Lower Austria and Burgenland). Basic descriptive analyses were conducted using absolute frequencies, percentages, means, and standard deviations, as appropriate. To evaluate the impact of sex, age, AB0 blood group and the blood donation period on the probability of being SARS-CoV-2 positive, multiple logistic regression with FLIC correction for rare events was applied $[9,10]$. Besides the above-mentioned variables, the interactions between sex and age as well as sex and AB0-blood group were also included in the model. For assessing statistical significance, the level $\alpha<0.05$ was used. All analyses were carried out using the statistical software $\mathrm{R}$ version 4.0.2 [11]. 


\section{Results}

\section{Seroprevalence rates for anti-SARS-CoV-2 in four Austrian federal states}

20,228 regular blood donors were tested for anti-SARSCoV-2 total antibody between 5th of June and 4th of December 2020 with an overall seroprevalence of $2.5 \%(=497$ blood donors). It should be noted that within the given period no fixed sample size was aimed on. The four different federal states showed comparable seroprevalence rates with highest numbers in Salzburg (2.7\% anti-SARS-CoV-2-positive). However, Salzburg contributed the highest number of blood donors screened, so putatively the seroprevalence of the other states is lower due to smaller numbers of screened donors (Table 1).
In a subgroup of 82 donor sera, which tested positive with Elecsys Anti-SARS-CoV-2, Wantai ELISA reacted positive in 74 cases. As the Wantai ELISA is considered adequate to neutralisation test for its sensitivity, the calculated specificity of the Elecsys Anti-SARS-CoV-2 is $90.24 \%$. The S/ $\mathrm{CO}$ (ACOV2) for donor sera considered false positive was ranging between 1.1 and 4.11 .

\section{Seroprevalence is not affected by sex and ABO blood group}

No statistically significant differences were observed concerning the anti-SARS-CoV-2 seroprevalence in women $(2.4 \%)$ or men $(2.5 \%$, multiple logistic regression: $p=0.9963$, see also Tables 1 and 2). Furthermore, we could not find significant differences concerning anti-SARS-CoV-2
Table 1 Seroprevalence of antiSARS-CoV-2 total antibody in Austrian blood donors

\begin{tabular}{|c|c|c|c|c|}
\hline & & $\begin{array}{l}\text { Anti-SARS-CoV-2 } \\
\text { positive }\end{array}$ & $\begin{array}{l}\text { Anti-SARS-CoV-2 } \\
\text { negative }\end{array}$ & Total \\
\hline 1 & Total: $N(\%)$ & $497(2.5)$ & $19,731(97.5)$ & 20,228 \\
\hline \multirow[t]{3}{*}{2} & \multicolumn{4}{|l|}{ Sex: $N$ (\% in subgroup) } \\
\hline & Women & $194(2.4)$ & 7774 (97.6) & 7968 \\
\hline & Men & $303(2.5)$ & $11,957(97.5)$ & 12,260 \\
\hline \multirow[t]{5}{*}{3} & \multicolumn{4}{|l|}{ Blood group: $N$ (\% in subgroup) } \\
\hline & 0 & $203(2.3)$ & $8468(97.7)$ & 8671 \\
\hline & A & $213(2.7)$ & $7812(97.3)$ & 8025 \\
\hline & $\mathrm{B}$ & $53(2.1)$ & $2455(97.9)$ & 2508 \\
\hline & $\mathrm{AB}$ & $28(2.7)$ & $996(97.3)$ & 1024 \\
\hline \multirow[t]{8}{*}{4} & Age: mean (standard deviation) & $40.2(14.3)$ & $41.6(14.4)$ & $41.6(14.4)$ \\
\hline & \multicolumn{4}{|l|}{ Age: $N$ (\% in subgroup) } \\
\hline & $18-25$ & $121(3.2)$ & $3623(96.8)$ & 3744 \\
\hline & $26-35$ & $87(2.2)$ & $3896(97.8)$ & 3983 \\
\hline & $36-45$ & $70(2.0)$ & $3486(98.0)$ & 3556 \\
\hline & $46-55$ & $133(2.8)$ & $4601(97.2)$ & 4734 \\
\hline & $56-65$ & $81(2.2)$ & $3535(97.8)$ & 3616 \\
\hline & $>65$ & $5(0.8)$ & $590(99.2)$ & 595 \\
\hline \multirow[t]{7}{*}{5} & \multicolumn{4}{|c|}{ Blood donation period: $N$ (\% in subgroup) } \\
\hline & 05.06.-04.07.2020 & $31(1.8)$ & $1647(98.2)$ & 1678 \\
\hline & 05.07.-04.08.2020 & $80(1.2)$ & $6702(98.8)$ & 6782 \\
\hline & 05.08.-04.09.2020 & $68(2.0)$ & $3307(98.0)$ & 3375 \\
\hline & 05.09.-04.10.2020 & $62(2.4)$ & 2507 (97.6) & 2569 \\
\hline & 05.10.-04.11.2020 & $76(3.0)$ & $2437(97.0)$ & 2513 \\
\hline & 05.11.-04.12.2020 & $180(5.4)$ & $3131(94.6)$ & 3311 \\
\hline \multirow[t]{5}{*}{6} & \multicolumn{4}{|l|}{ Federal state: $N$ (\% in subgroup) } \\
\hline & Burgenland & $3(0.4)$ & 849 (99.6) & 852 \\
\hline & Lower Austria & $76(2.3)$ & $3216(97.7)$ & 3292 \\
\hline & Salzburg & $360(2.7)$ & $13,004(97.3)$ & 13,364 \\
\hline & Vienna & $58(2.1)$ & $2662(97.9)$ & 2720 \\
\hline
\end{tabular}

Results are sorted according to sex (2), AB0-blood group (3), age (4), blood donation period (5) and federal state of blood donation (6). Total numbers of blood donors screened are shown in Sect. (Introduction) 
Table 2 Multiple logistic regression analysis with FLIC correction for anti-SARS-CoV-2 seroprevalence rates

\begin{tabular}{|c|c|c|}
\hline Variable & Odds ratio $(95 \% \mathrm{CI})$ & $p$ value \\
\hline \multicolumn{3}{|l|}{ Sex } \\
\hline Female & $1.00(0.65-1.53)$ & 0.9963 \\
\hline \multicolumn{3}{|l|}{ Blood group } \\
\hline A & $1.14(0.89-1.46)$ & 0.3075 \\
\hline B & $0.85(0.56-1.25)$ & 0.4267 \\
\hline $\mathrm{AB}$ & $1.36(0.80-2.18)$ & 0.2443 \\
\hline \multicolumn{3}{|l|}{ Age } \\
\hline $18-25$ & Reference & - \\
\hline $26-35$ & $0.64(0.44-0.94)$ & 0.0215 \\
\hline $36-45$ & $0.78(0.54-1.13)$ & 0.1888 \\
\hline $46-55$ & $0.91(0.65-1.27)$ & 0.5657 \\
\hline $56-65$ & $0.71(0.49-1.02)$ & 0.0650 \\
\hline$>65$ & $0.22(0.04-0.63)$ & 0.0026 \\
\hline \multicolumn{3}{|l|}{ Blood donation period } \\
\hline 05.06.-04.07.2020 & Reference & - \\
\hline 05.07.-04.08.2020 & $0.62(0.42-0.96)$ & 0.0321 \\
\hline 05.08.-04.09.2020 & $1.07(0.70-1.66)$ & 0.7580 \\
\hline 05.09.-04.10.2020 & $1.30(0.85-2.03)$ & 0.2274 \\
\hline 05.10.-04.11.2020 & $1.62(1.08-2.51)$ & 0.0199 \\
\hline $05.11 .-04.12 .2020$ & $3.03(2.09-4.52)$ & $<0.0001$ \\
\hline \multicolumn{3}{|l|}{ Sex $\times$ age } \\
\hline Female, 18-25 & Reference & - \\
\hline Female, 26-35 & $1.07(0.61-1.88)$ & 0.8058 \\
\hline Female, 36-45 & $0.42(0.21-0.79)$ & 0.0074 \\
\hline Female, $46-55$ & $0.85(0.51-1.42)$ & 0.5391 \\
\hline Female, 56-65 & $1.00(0.55-1.79)$ & 0.9969 \\
\hline Female, $>65$ & $2.54(0.47-15.92)$ & 0.2714 \\
\hline \multicolumn{3}{|l|}{ Sex $\times$ blood group } \\
\hline Female, 0 & Reference & - \\
\hline Female, A & $1.12(0.75-1.68)$ & 0.5707 \\
\hline Female, B & $1.31(0.70-2.43)$ & 0.3928 \\
\hline Female, AB & $0.88(0.38-1.98)$ & 0.7652 \\
\hline
\end{tabular}

Data are presented in groups according to sex, blood group, age and donation period. The symbol " $x$ " indicates interaction terms

seroprevalence between the AB0 blood groups (Tables 1, 2 and Fig. 1).

\section{Age significantly affects the anti-SARS-CoV-2 seroprevalence}

Concerning the age of blood donors, we found a significantly higher seroprevalence for donors aged 18-25 compared to other age groups (3.2\% compared to $2 \%$ as a mean value for the other groups) (Table 1 and Fig. 2). Multiple logistic regression analysis revealed that the age of the blood donors is an important factor: Blood donors show substantially lower odds ratio (OR) when 26-35 years old
$(0.64, p=0.0215)$ or older than 56 years (56-65 years: 0.71 , $p=0.0650 ;>65$ years: $0.22, p=0.0026)$ compared to the reference age group 18-25 years, indicating a lower risk for SARS-CoV-2 infections. Blood donors aged 36-55 years show similar odd ratios compared to the reference group 18-25 years (Table 2). In blood donors aged $18-25$, seroprevalences were about the same in men and women. Yet, for donors between 36 and 45 years, seroprevalences were markedly lower for women compared to men (Table 2 and Fig. 2). The multiple logistic regression analysis further revealed, that women aged 36-45 show a significantly lower seroprevalence rate compared to women of the reference group $18-25$ years (OR $0.42, p=0.0074)$ (Table 2$)$.

\section{Blood donation period reflects rising seroprevalence rates after lockdowns}

Comparing the different blood donation periods (Tables 1, 2 and Fig. 3), different seroprevalence rates can be observed: At the beginning of this study, the seroprevalence rate was $1.8 \%$. This rate was even reduced in the following period (05.07.-04.08.2020): 1.2\% (OR 0.62, CI 95\% 0.42-0.96, $p=0.0321)$. After 04.08.2020, seroprevalence rates were constantly rising $(2.0 \%$ for $05.08 .-04.09 .2020,2.4 \%$ for 05.09.-04.10.2020, 3.0\% for 05.10.-04.11.2020 and 5.4\% for 05.11.-04.12.2020). Odd ratios of the multiple logistic regression analysis show rising odds ratios $>1.0$, confirming significantly increased seroprevalence rates from 05.10 .2020 on (05.10.-04.11.2020: odds ratio $1.62, p=0.0199$; 05.11.-04.12.2020: odds ratio 3.03, $p<0.0001$ ) (Table 2).

\section{Discussion}

Compared to other European regions, e.g. Lombardy (Italy) with a seroprevalence of 23\% [12] or Madrid (Spain) with a seroprevalence rate of $11.5 \%$ [13], the overall seroprevalence rate of $2.5 \%$ for SARS-CoV-2 determined in our study for the four Austrian federal states is rather low. Our data are comparable to the $2.7 \%$ seroprevalence rate determined by a study conducted in the Netherlands [14]. However, in contrast to this study, our data did not reveal significant local differences between the federal states. In the first month of our study, we determined a seroprevalence rate of $1.8 \%$, which even decreased to $1.2 \%$ for the period 05.07.-04.08.2020. Our data show an increasing trend of seroprevalence, ascending to $5.4 \%$ between 05.11 and 04.12 .2020 . The low seroprevalence rates at the beginning of our study could be explained by lower infection rates at an earlier stage of the pandemic. A further explanation could be successful preventive interventions, such as the first Austrian lockdown (16.03.-01.05.2020), social distancing and other hygiene measures (e.g. facemasks), as also indicated by others [15, 
Fig. 1 Seroprevalence rates for anti-SARS-CoV-2 total antibody according to $\mathrm{AB}$ 0-blood group and sex. AB0-blood group and sex do not significantly influence seroprevalence rates. $\mathrm{m}$-male, $\mathrm{f}$-female
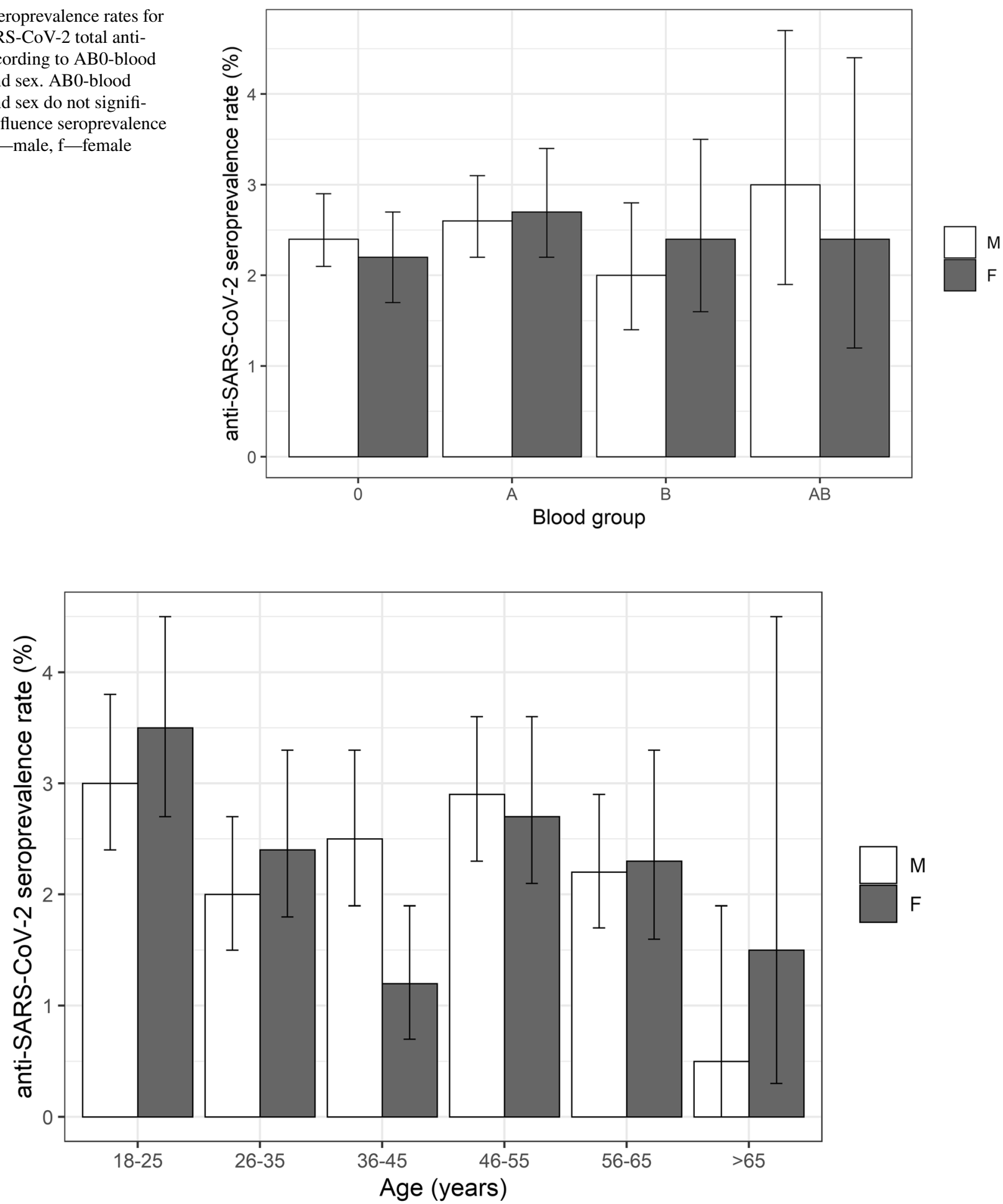

Fig. 2 Seroprevalence rates for anti-SARS-CoV-2 total antibody sorted according to sex and age groups. Age groups as indicated, $\mathrm{m}-\mathrm{male}, \mathrm{f}-$ female 


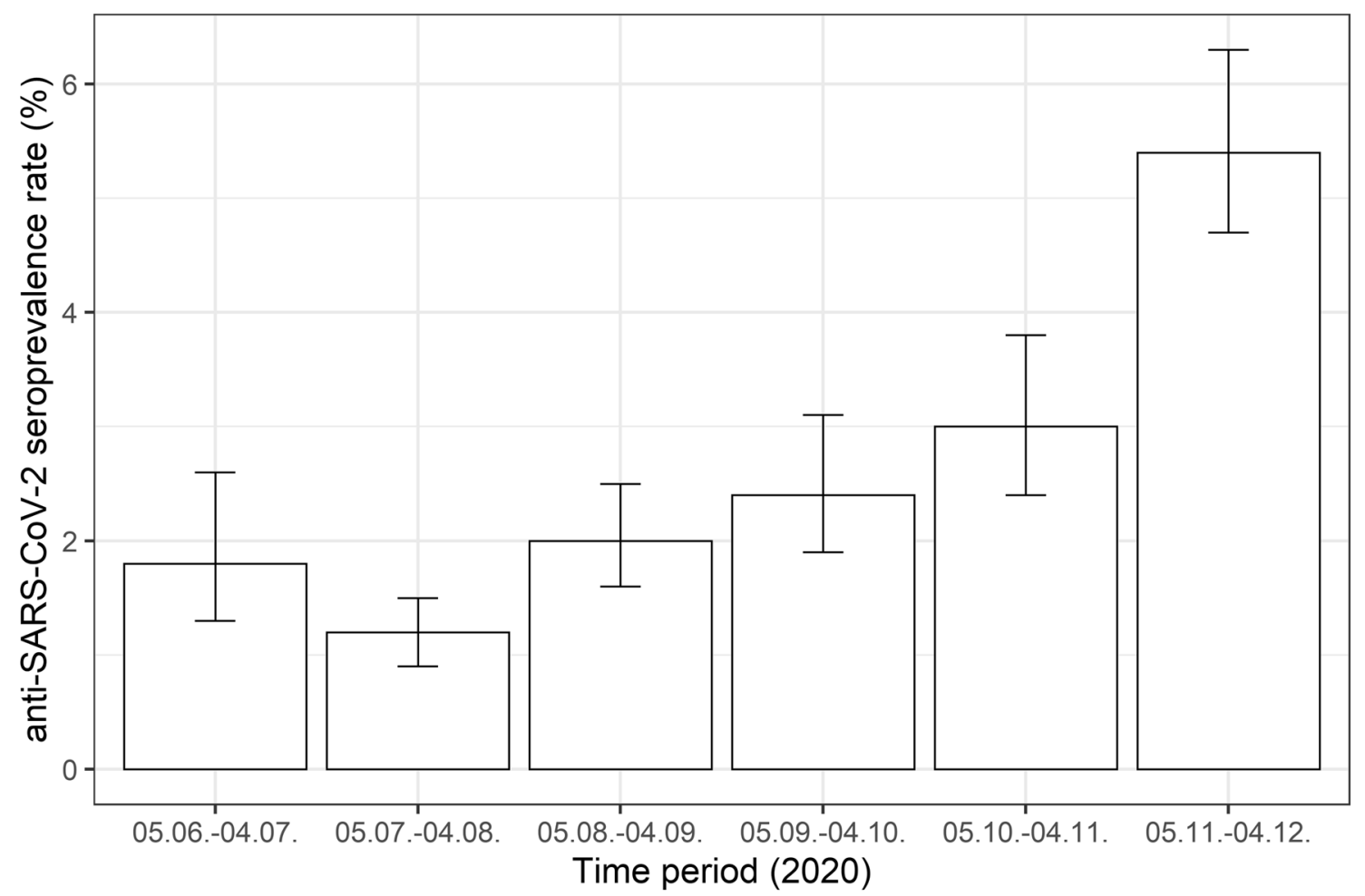

Fig. 3 Seroprevalence rates for anti-SARS-CoV-2 total antibody from 05.06. to 04.12.2020

16]. After the end of the first Austrian lockdown, the SARSCoV-2 infection rates and thus, as observed in our study, with some delay the seroprevalence rates, were rising again.

We did not find significant differences in the seroprevalence between women and men. A similar observation was described by another study that identified similar prevalence rates between women and men, even though men were more at risk of severe COVID-19 outcomes [17]. Similarly, a review of several population-based studies concluded that the anti-SARS-CoV-2 seroprevalence between men and women is not significantly different [18].

In contrast to other studies $[19,20]$, which indicated that blood group 0 might be less at risk of being infected, our data did not reveal an impact of AB0-blood groups on antiSARS-CoV-2 seroprevalence rates. These contradictory results may be explained by different sizes of study groups screened and different test systems and strategies applied. Gallian et al. used neutralizing antibody tests. However, there are studies indicating that not all individuals who recovered from a SARS-CoV-2 infection express detectable levels of neutralizing antibodies [21]. Zietz et al. used swab tests, which were recently reported to differ substantially in analytical sensitivity and specificity [22].

Furthermore, our data revealed significantly higher seroprevalence rates for donors aged 18-25 compared to donors aged 26-35 and donors aged 56 years and older, corroborating the seroprevalence studies from Brazil [23], the
Netherlands [14] and Kenya [24]. This could be explained by age-related more active social behaviour during the non-lockdown periods in this youngest group of blood donors. The similar seroprevalence rates for blood donors aged between 36 and 55 years compared to the group aged 18-25 could putatively be related to more social obligations (such as work, caring for children and elderly people) forcing adults aged 36-55 years to have more encounters and therefore putting them at higher risk for viral infections than other age groups. It is important to note that women of the age group 36-45 show a significant lower seroprevalence rate compared to women of the reference group (18-25 years). Furthermore, blood donors aged 65 and older show the lowest seroprevalence rates out of all distinguished age groups. This could be explained by a smaller sample size compared to other age groups, but also by their awareness of their categorisation as a risk group leading to higher precaution in social interactions and concerning hygiene measures.

The presented study has some limitations: It cannot be extrapolated to children and young individuals ( $<18$ years), adults with more severely impaired health and elderly aged higher than 72 years. In addition, $60 \%$ of donors tested positive (resonating with the number of total donors) were male. This might be due to the fact, that men usually have a higher body weight $(>50 \mathrm{~kg}$ ) and show higher $\mathrm{Hb}$ values compared to woman, thus fulfilling the criteria for blood donation more 
easily. Therefore, the tested population does not fully represent the demographics of the Austrian population with 50.8\% females (https://www.statistik.at/web_de/statistiken/ menschen_und_gesellschaft/soziales/gender-statistik/demog raphie/index.html, accessed 25.01.2021). In addition, our testing strategy was to screen for total anti-SARS-CoV-2 antibodies. However, the method used does not allow concluding on the presence of neutralising antibodies against SARS-CoV-2. Neutralisation tests would be necessary to prove the functionality of these antibodies. Furthermore, it should be considered that the seroprevalence in this study group may be overestimated by around $10 \%$ based on the calculated specificity of the applied ACOV2 screening test. We therefore also compared our results with an official public data report from the Austrian Social Science Data Archive (AUSSADA) (https://data.aussda.at/dataset.xhtml? persistentId=doi: 10.11587/G3C2CS, accessed 30.04.2021), that reports $3.1 \%$ seroprevalence on average in mid-November 2020 [95\% confidence interval: $2.6-3.5 \%$ ]. This data set includes people aged 16 and older living in private Austrian households. Even though the seroprevalence of a different group of people was investigated, the seroprevalence of $3.1 \%$ matches our finding for blood donors with $3.0 \%$ within the same period.

In conclusion, our study reveals that the seroprevalence of anti-SARS-CoV-2 is associated with age, but not with sex or AB0 blood group. Furthermore, the seroprevalence varies according to blood donation period, indicating that lockdowns help to avoid SARS-CoV-2 dissemination. Even though SARS-CoV-2 infections rates are constantly rising worldwide, a seroprevalence rate of $5.4 \%$ within a certain population is far too low to reach potential herd immunity within a short period without a complete overload of the health system. Therefore, hygienic measures, social distancing and a vaccination are important and necessary to prevent further SARS-CoV-2 dissemination and thus further burden for health systems and death cases worldwide. Since SARSCoV-2 infections may show only mild symptoms or be even asymptomatic, many infections might be completely unnoticed. Therefore, screening blood donors as a representative group for the adult population could be a valid tool to determine more exact case numbers of SARS-CoV-2 infections within a population.

Acknowledgements The authors thank Nina Held and Monica Pascariuc, MSc for excellent technical assistance.

Authors' contributions LW contributed to data collection and analysis. LG and ADH contributed to data collection, GZ and CG performed data analysis and interpretation. CJ contributed to data collection and study design, VN performed data analysis and contributed to manuscript writing. ER contributed to study design and manuscript writing. SLP contributed to study design and data collection, performed data analysis and interpretation and wrote the manuscript. All authors read and approved the final manuscript.
Funding Open access funding provided by Paracelsus Medical University. Georg Zimmermann gratefully acknowledges the support of the WISS 2025 project 'IDA-Lab Salzburg' (20204-WISS/225/197-2019 and 20102-F1901166-KZP).

Data availability The datasets generated and analysed during the current study are not publicly available due to data protection, but are available in an anonymized manner from the corresponding author on reasonable request.

\section{Declarations}

Conflict of interest The authors declare to have no conflicts of interest and no competing interests.

Consent to participate Informed consent was obtained from all individual participants included in the study.

Consent for publication All blood donors signed informed consent on the use of leftover material for research purposes.

Ethical approval In this study, human residual serum for routine laboratory diagnostics as conducted in the course of standard blood donation workup according to European and local legal regulations was used. All donors of the samples used signed informed consent on the use of leftover material for research purposes. The work described has been carried out in accordance with the 1964 Helsinki Declaration and its later amendments or comparable ethical standards. Samples were processed anonymously to protect privacy of each donor.

Open Access This article is licensed under a Creative Commons Attribution 4.0 International License, which permits use, sharing, adaptation, distribution and reproduction in any medium or format, as long as you give appropriate credit to the original author(s) and the source, provide a link to the Creative Commons licence, and indicate if changes were made. The images or other third party material in this article are included in the article's Creative Commons licence, unless indicated otherwise in a credit line to the material. If material is not included in the article's Creative Commons licence and your intended use is not permitted by statutory regulation or exceeds the permitted use, you will need to obtain permission directly from the copyright holder. To view a copy of this licence, visit http://creativecommons.org/licenses/by/4.0/.

\section{References}

1. Wu F, Zhao S, Yu B, Chen YM, Wang W, Song ZG, Hu Y, Tao ZW, Tian JH, Pei YY, Yuan ML, Zhang YL, Dai FH, Liu Y, Wang QM, Zheng JJ, Xu L, Holmes EC, Zhang YZ. A new coronavirus associated with human respiratory disease in China. Nature. 2020;579:265-9. https://doi.org/10.1038/s41586-020-2008-3.

2. Zhu N, Zhang D, Wang W, Li X, Yang B, Song J, Zhao X, Huang B, Shi W, Lu R, Niu P, Zhan F, Ma X, Wang D, Xu W, Wu G, Gao GF, Tan W, China Novel Coronavirus Investigating and Research Team. A novel coronavirus from patients with pneumonia in China, 2019. N Engl J Med. 2020;382:727-33. https://doi.org/ 10.1056/NEJMoa2001017.

3. Drosten C, Gunther S, Preiser W, van der Werf S, Brodt HR, Becker S, Rabenau H, Panning M, Kolesnikova L, Fouchier RA, Berger A, Burguiere AM, Cinatl J, Eickmann M, Escriou N, Grywna K, Kramme S, Manuguerra JC, Muller S, Rickerts V, Sturmer M, Vieth S, Klenk HD, Osterhaus AD, Schmitz H, Doerr HW. Identification of a novel coronavirus in patients with severe 
acute respiratory syndrome. N Engl J Med. 2003;348:1967-76. https://doi.org/10.1056/NEJMoa030747.

4. Zaki AM, van Boheemen S, Bestebroer TM, Osterhaus AD, Fouchier RA. Isolation of a novel coronavirus from a man with pneumonia in Saudi Arabia. N Engl J Med. 2012;367:1814-20. https://doi.org/10.1056/NEJMoa1211721.

5. Kim GU, Kim MJ, Ra SH, Lee J, Bae S, Jung J, Kim SH. Clinical characteristics of asymptomatic and symptomatic patients with mild COVID-19. Clin Microbiol Infect. 2020;26:948 e1-948 e3. https://doi.org/10.1016/j.cmi.2020.04.040.

6. Machhi J, Herskovitz J, Senan AM, Dutta D, Nath B, Oleynikov MD, Blomberg WR, Meigs DD, Hasan M, Patel M, Kline P, Chang RC, Chang L, Gendelman HE, Kevadiya BD. The natural history, pathobiology, and clinical manifestations of SARS-CoV-2 infections. J Neuroimmune Pharmacol. 2020;15:359-86. https:// doi.org/10.1007/s11481-020-09944-5.

7. Uyoga S, Adetifa IMO, Karanja HK, Nyagwange J, Tuju J, Wanjiku P, Aman R, Mwangangi M, Amoth P, Kasera K, Ng'ang'a W, Rombo C, Yegon C, Kithi K, Odhiambo E, Rotich T, Orgut I, Kihara S, Otiende M, Bottomley C, Mupe ZN, Kagucia EW, Gallagher KE, Etyang A, Voller S, Gitonga JN, Mugo D, Agoti CN, Otieno E, Ndwiga L, Lambe T, Wright D, Barasa E, Tsofa B, Bejon P, Ochola-Oyier LI, Agweyu A, Scott JAG, Warimwe GM. Seroprevalence of anti-SARS-CoV-2 IgG antibodies in Kenyan blood donors. Science. 2020. https://doi.org/10.1126/science. abe1916.

8. Weidner L, Gansdorfer S, Unterweger S, Weseslindtner L, Drexler C, Farcet M, Witt V, Schistal E, Schlenke P, Kreil TR, Jungbauer C. Quantification of SARS-CoV-2 antibodies with eight commercially available immunoassays. J Clin Virol. 2020;129:104540. https://doi.org/10.1016/j.jcv.2020.104540.

9. Puhr R, Heinze G, Nold M, Lusa L, Geroldinger A. Firth's logistic regression with rare events: accurate effect estimates and predictions? Stat Med. 2017;36:2302-17. https://doi.org/10.1002/sim. 7273.

10. G. Heinze, M. Ploner, L. Jiricka, logistf: Firth's Bias-Reduced Logistic Regression. R package version 1.24., 2020.

11. R-Core-Team. A language and environment for statistical computing. Vienna: R Foundation for Statistical Computing; 2020.

12. Percivalle E, Cambie G, Cassaniti I, Nepita EV, Maserati R, Ferrari A, Di Martino R, Isernia P, Mojoli F, Bruno R, Tirani M, Cereda D, Nicora C, Lombardo M, Baldanti F. Prevalence of SARS-CoV-2 specific neutralising antibodies in blood donors from the Lodi Red Zone in Lombardy, Italy, as at 06 April 2020. Euro Surveill. 2020;25:2001031. https://doi.org/10.2807/15607917.ES.2020.25.24.2001031

13. Pollan M, Perez-Gomez B, Pastor-Barriuso R, Oteo J, Hernan MA, Perez-Olmeda M, Sanmartin JL, Fernandez-Garcia A, Cruz I, de Fernandez Larrea N, Molina M, Rodriguez-Cabrera F, Martin M, Merino-Amador P, Leon Paniagua J, Munoz-Montalvo JF, Blanco F, Yotti R, ENE-COVID Study Group. Prevalence of SARS-CoV-2 in Spain (ENE-COVID): a nationwide, population-based seroepidemiological study. Lancet. 2020;396:535-44. https://doi.org/10.1016/S0140-6736(20)31483-5.

14. Slot E, Hogema BM, Reusken C, Reimerink JH, Molier M, Karregat JHM, IJIst J, Novotny VMJ, van Lier RAW, Zaaijer HL. Low
SARS-CoV-2 seroprevalence in blood donors in the early COVID19 epidemic in the Netherlands. Nat Commun. 2020;11:5744. https://doi.org/10.1038/s41467-020-19481-7.

15. Davies NG, Barnard RC, Jarvis CI, Russell TW, Semple MG, Jit M, Edmunds WJ, C.-W.G. Centre for Mathematical Modelling of Infectious Diseases, I.C. investigators. Association of tiered restrictions and a second lockdown with COVID-19 deaths and hospital admissions in England: a modelling study. Lancet Infect Dis. 2020. https://doi.org/10.1016/S1473-3099(20)30984-1.

16. Han E, Tan MMJ, Turk E, Sridhar D, Leung GM, Shibuya K, Asgari N, Oh J, Garcia-Basteiro AL, Hanefeld J, Cook AR, Hsu LY, Teo YY, Heymann D, Clark H, McKee M, Legido-Quigley H. Lessons learnt from easing COVID-19 restrictions: an analysis of countries and regions in Asia Pacific and Europe. Lancet. 2020;396:1525-34. https://doi.org/10.1016/S0140-6736(20) 32007-9.

17. Jin JM, Bai P, He W, Wu F, Liu XF, Han DM, Liu S, Yang JK. Gender differences in patients with COVID-19: focus on severity and mortality. Front Public Health. 2020;8:152. https://doi.org/ 10.3389/fpubh.2020.00152.

18. Lai CC, Wang JH, Hsueh PR. Population-based seroprevalence surveys of anti-SARS-CoV-2 antibody: an up-to-date review. Int J Infect Dis. 2020;101:314-22. https://doi.org/10.1016/j.ijid.2020. 10.011 .

19. Zietz M, Zucker J, Tatonetti NP. Associations between blood type and COVID-19 infection, intubation, and death. Nat Commun. 2020;11:5761. https://doi.org/10.1038/s41467-020-19623-x.

20. Gallian P, Pastorino B, Morel P, Chiaroni J, Ninove L, de Lamballerie X. Lower prevalence of antibodies neutralizing SARS-CoV-2 in group O French blood donors. Antiviral Res. 2020;181:104880. https://doi.org/10.1016/j.antiviral.2020.104880.

21. Wu F, Wang A, Liu M, Wang Q, Chen J, Xia S, Ling Y, Zhang Y, Xun J, Lu L, Jiang S, Lu H, Wen Y, Huang J. Neutralizing antibody responses to SARS-CoV-2 in a COVID-19 recovered patient cohort and their implications. medRxiv. 2020. https://doi. org/10.1101/2020.03.30.20047365.

22. Surkova E, Nikolayevskyy V, Drobniewski F. False-positive COVID-19 results: hidden problems and costs. Lancet Respir Med. 2020;8(12):1167-8. https://doi.org/10.1016/S2213-2600(20) 30453-7.

23. AmorimFilho L, Szwarcwald CL, Mateos SOG, Leon A, Medronho RA, Veloso VG, Lopes JIF, Porto L, Chieppe A, Werneck GL, de GrupoHemorioPesquisaem C. Seroprevalence of anti-SARS-CoV-2 among blood donors in Rio de Janeiro, Brazil. Rev Saude Publica. 2020;54:69. https://doi.org/10.11606/s15188787.2020054002643.

24. Uyoga S, Adetifa IMO, Karanja HK, Nyagwange J, Tuju J, Wanjiku P, Aman R, Mwangangi M, Amoth P, Kasera K, Ng'ang'a W, Rombo C, Yegon C, Kithi K, Odhiambo E, Rotich T, Orgut I, Kihara S, Otiende M, Bottomley C, Mupe ZN, Kagucia EW, Gallagher KE, Etyang A, Voller S, Gitonga JN, Mugo D, Agoti CN, Otieno E, Ndwiga L, Lambe T, Wright D, Barasa E, Tsofa B, Bejon P, Ochola-Oyier LI, Agweyu A, Scott JAG, Warimwe GM. Seroprevalence of anti-SARS-CoV-2 IgG antibodies in Kenyan blood donors. Science. 2021;371:79-82. https://doi.org/10.1126/ science.abe1916. 